\title{
Milligram per Kilogram per Hour
}

National Cancer Institute

\section{Source}

National Cancer Institute. Milligram per Kilogram per Hour. NCI Thesaurus. Code C71362.

A dose calculation unit equal to one thousandth of a gram of a preparation per one kilogram of body mass administered per unit of time equal to one hour. 